\title{
Work in Progress: The Construction of a New First-Year Engineering Pro- gram
}

\section{Dr. George D. Ricco, University of Kentucky}

George D. Ricco is an assistant professor of electrical and computer engineering at the University of Kentucky. He focuses his work between teaching in the first-year engineering program at UK and research in student progression. Previously, he was the KEEN Program Coordinator at Gonzaga University in the School of Engineering and Applied Science. He completed his doctorate in engineering education from Purdue University's School of Engineering Education. Previously, he received an M.S. in earth and planetary sciences studying geospatial imaging, and an M.S. in physics studying high-pressure, hightemperature FT-IR spectroscopy in heavy water, both from the University of California, Santa Cruz. He holds a B.S.E. in engineering physics with a concentration in electrical engineering from Case Western Reserve University. His academic interests include longitudinal analysis, visualization, semantics, team formation, gender issues, existential phenomenology, and lagomorph physiology.

\section{Dr. Janet K. Lumpp, University of Kentucky}


Work in Progress: The Construction of a New First-Year Engineering Program 


\section{Abstract and Background}

This paper describes the first steps in building, observing, and evaluating a new first-year engineering (FYE) program at a flagship R1 university. We start from the beginning, with a brief history of the program, and move into the construction of it as it exists today.

We feel there are two items in particular that are of significant interest to the greater community. First there are unique problems that arise when the program is constructed (and expanded into satellite campuses). How to address these issues is of fundamental importance to any emergent FYE program. Also, the nature of flexibility among instructors is a topic frequently ignored by FYE programs and not significantly addressed in the literature - a topic among our program colloquially referred to as "going rogue." Within our program, we allow significant deviation to incorporate individual teaching styles while still requiring a core set of exercises to be accomplished by every course section.

Starting in 2013, the Dean and Associate Dean for Academics in the College of Engineering visited established FYE programs and began planning implementation of a program suited to our own college. Improving student retention was the primary goal and the secondary goal was to reduce changes of major within the college to help students choose an appropriate major and pursue it to graduation. This phenomenon is not endemic to our program and has been documented by others (Froyd \& Ohland, 2005) Initial discussions with a working group explored what course changes would be necessary to develop an introductory curriculum acceptable to all nine degree programs. In 2015, a director was appointed from within the college with 50\% effort assigned to administering the program. With the help of department representatives, a three-course sequence was envisioned to replace the discipline specific " 101 " courses, either of two computer programming courses and the general education requirement for Inquiry into Arts \& Creativity. All students must be in pre-calculus or beyond to be admitted to the college. The balance of credit hours and course enrollments over the first two semesters requires that some students take chemistry first and others take physics first with or without the labs. The course outlines were approved and all of the degree program curricula were changed in one combined proposal.

Facets and Decisions Made

\section{Information sessions}

Each student is required to attend four FYE Information Session (FYE-IS) throughout the course. Every FYE-IS session is offered in the evening, nearly every weekday, for a period of four weeks in the first semester for two rounds. All nine majors at the College sent full professors (and in some cases multiple full professors, graduate students, and undergraduates) to speak to the students about the unique facets of each department, along with undergraduate opportunities, student groups based within the department, and more.

Parity of team members

While the teaching team consists of multiple teaching faculty, special title series faculty (STS) on the tenure-track, and tenured full professors (including one associate dean), each 
member of the team is considered equal to others, and contributes to the curriculum of the courses taught. All are referred to as professors in and out of class by students.

\section{Construction of the Learning Objectives}

While the team could not find modern research on the subject, anecdotal evidence from interviews with other FYE teams indicates that many schools have outcomes without objectives the two being radically different constructs. In the appendices, we have included some of our learning objectives. Perhaps most ubiquitous from our conversations with other programs is the nature of how to provide students with opportunities to explore other majors (guided or directed choice) while still helping them feel grounded in their own tentative choice. From informal conversations, it is clear that our students have a perception of engineering that may not necessarily be real - and certainly that difficulty is key (Stevens, 2007). Part of the goal of learning objectives within our program is to make them available to students and reiterate them throughout the course sequences in order to demonstrate that difficulty is not the endgame, nor is it productive to think in that fashion.

Use of Reflective and Liberative Pedagogies

Both the first and third introductory course make significant use of reflective responses and self-actualizing modalities (Hirsch \& McKenna, 2008; Riley, 2003). Students throughout the first and third courses are asked to reflect upon various exercises and asked to contribute to the exercises through feedback. In one example, students were asked to give general rules of thumb for a machine floor optimization problem. Due to some unique and unexpected directions the students took, a reflection assignment was designed, and the proposed exam questions for the module changed based on student engagement and proclivity with various facets of the assignment. Another example of liberative philosophies comes to us from a few of our faculty who invite students to critique and analyze the course syllabi the first day while sitting in a circle. The conversations reported by the faculty indicate that students begin sharing information they did not know would help them in their engineering careers.

The third course in the sequence being more of a team design course, employs methods from other design courses from FYE institutions in contact with our team (Adams, 2002; Atman et al., 2007; Crismond \& Adams, 2012; Turns et al., 2006). One engagement protocol that mixes best practices from Adams' work and is similar to the liberative ones employed by Riley is used by one faculty member who requires all students to stand while discussing an element of design from the project, and the next speaker must amplify the previous student's statement in terms of his own. Students in this scenario must engage in synthetic and reflective thinking each time they want to contribute to a design conversation.

\section{Use of Materials from Major Courses}

One of the most important aspects of this course sequence in FYE is to help students get a glimpse of "real" engineering. In this case, this means providing them opportunities to reflect upon their major using tools developed by individual majors. The third course in the sequence employs elements from directly from chemical, biomedical, mechanical, mining, civil, electrical, 
and computer science. Another reason this is employed is because all students matriculate under a major designation, thus relieving them of the anxiety of being undecided or having to make a first choice during the school year (Brown \& Strange, 1981; Titley \& Titley, 1980). Another more subversive element lies in the fact that although capstone courses are ubiquitous and many agree helpful for engineering students, the link between first and senior year experiences is not as well understood by the engineering education community (Howe, 2010). Some of the materials we use in the FYE program are ones that have been discussed with and developed with faculty from the second year courses at our institution. The goal being to give them a glimpse of items they will reiterate within a year that individual majors believe will be important for junior and senior year studies. Lastly, providing these useful skills in a comfortable learning environment attenuates the feeling that the first year course sequence is a gatekeeper or barrier. Students are highly aware of such courses and when they perceive they're being "weeded out," their behavior changes (Suresh, 2007).

\section{Administrative Concerns}

Administrative issues are handled by one centralized director, with autonomy to direct team members to tasks as needed. The lack of an assistant director is intentional and protects tenure-track faculty members from over commitment to administrative responsibilities beyond routine committee work. The director positive answers to the assistant dean in the college of engineering, as the courses themselves are housed under the dean's office, and not any one college.

\section{Housing within departments}

Every team member has a home within the relevant department. All team members have voting privileges at their department meetings. All tenure-track members have offices within their departments (and research space where necessary). This sets up a structure where each team member is engaged in conversations and privy to departmental opinions about the FYE program. In departmental meetings and retreats where questions are asked about perceptions about the FYE program, FYE team members must recuse themselves, but are not limited or censured from speaking to fellow faculty members otherwise.

Methodology and Incoming Data

The majority of work thus far has encompassed student course responses, primary survey analysis, and preliminary results from focus groups. The focus group interviews followed a semistructured protocol revolving around questions of: general understanding of the program and the reason for its establishment; potential benefits of the program for the university and the college; concerns about the shift in curriculum model; and views of what constitutes success or failure of such a program. The general methodology for our qualitative interview process follows that outlined in by Strauss (Strauss, 1987). An external evaluation center performed the interviews and small focus groups to avoid ethical conflicts. 
Ethnographic data has consisted of informal notes and journals kept by members of the FYE team. The goal of such an informal structure is to preserve natural observations (Anderson, 2003). Since the first year of the course has not been completed, and we have not had an external evaluator to give an independent view of the notes (along with a coding schema), they will not be ready for presentation until the summer.

Finally, multiple historical artifacts (already mentioned by students and faculty in interviews and by students in course responses) exist that allow for triangulation and multiple perspectives from outside evaluators. First, the history of the course syllabus and learning objectives and outcomes provide a robust opportunity to study the evolution of the course. Second, the navigation of the team relative to the course objectives and outcomes - especially with respect to changing and molding the examinations - gives another dynamic view of how a FYE team changes in response to overarching course structures.

\section{Current Results and Discussion}

Student perceptions from feedback

The student feedback ( $\mathrm{N}=893$ complete) consisted of traditional surveys of satisfaction with the course, teacher competency, and chances for open response. So far, with $\mathrm{N}=80$ of the essay responses fully coded and a preliminary coding structure for the others in development, the following themes emerged:

1. Students are hyper-aware of circumstances of the class. Students had an implicit and explicit awareness of the course's effect on the college and the greater context at the university itself. While no students indicated (so far in the analysis) the new program being a primary reason for attending the university (not necessarily a negative), they are aware that this course intends to prepare them for their majors. One student even made a plea of disappointment the he/she felt deviations from the curriculum would rob him/her of information that the departments wanted to impart! Even a negative statement can be positive when seen from the vantage point that such a student feels that the information in the slide deck and homework is directly related to future success.

2. Students are forgiving of various course shortcomings - especially in a contextual environment such as a new program. Students made explicit mention many times of the fact they understood how some modules would seem different because the course is new. Students seem to understand at the very least that being the first time through there would be setbacks, changes, and sometimes things would break. Even the intermittent wi-fi in the new classroom used for the course wasn't a significant issue for students.

3. Generally, students understood the themes of the course as outlined in the course learning objectives and learning outcomes. Although at this juncture, we are not sure 
if the students read (or even took seriously) the learning objective and outcomes, their surveys indicate that they run congruent to the student take-away experience.

a. Exposure to the disciplines. The students indicated that the course prepared them - in general - to be exposed and gain a working knowledge of engineering disciplines other than the one of their choosing. This extended from just general exposure of concepts to specific problems and learning sessions.

b. Students understood the concept of guided or directed choice - the philosophy that FYE is a vessel to guide students to the right choice of major, whether this is within the college of engineering or another at the university.

\section{Conclusion and Future Work}

Currently, there is significant work to finish that will be ready within a six-month time frame. We are excited to share the results of the independent evaluators with the engineering education community, and that work coupled with faculty observations will allow us to triangulate our coding schema.

Furthermore, a few interesting items for future work have already arisen. For example, while we are aware of work surrounding students misjudging the enterprise of engineering as a reason to choose it for a major, we are not aware of work describing students feeling deprived of notes they think they should be running through in class because they believe another department wants them to gain proclivity with them. 


\section{References}

Adams, R. (2002). Understanding Design Iteration: Representations from An Empirical Study. Paper presented at the International Conference of Design Research Society.

Anderson, E. (2003). A place on the corner (2nd Edition ed.). Chicago: University of Chicago Press.

Atman, C. J., Adams, R. S., Cardella, M. E., Turns, J., Mosborg, S., \& Saleem, J. (2007). Engineering design processes: A comparison of students and expert practitioners. Journal of Engineering Education, 96(4), 359-379.

Brown, G. S., \& Strange, C. (1981). The Relationship of Academic Major and Career Choice Status to Anxiety Among College Freshmen. Journal of Vocational Behavior, 19(3), 328-334. doi:10.1016/0001-8791(81)90067-1

Crismond, D. P., \& Adams, R. S. (2012). The Informed Design Teaching and Learning Matrix. Journal of Engineering Education, 101(4), 738-797. doi:10.1002/j.2168-9830.2012.tb01127.x

Froyd, J. E., \& Ohland, M. W. (2005). Integrated Engineering Curricula. Journal of Engineering Education, 94(1), 147-164. doi:10.1002/j.2168-9830.2005.tb00835.x

Hirsch, P. L., \& McKenna, A. F. (2008). Using Reflection to Promote Teamwork Understanding in Engineering Design Education. International Journal of Engineering Education.

Howe, S. (2010). Where are we now? Statistics on capstone courses nationwide. Advances in Engineering Education, 2(Compendex), 1-27.

Riley, D. (2003). Employing Liberative Pedagogies in Engineering Education. Journal of Women and Minorities in Science and Engineering, 9(2), 137-158.

Stevens, R., Daniel M. Amos, Lari Garrison, and Andy Jocuns. (2007). Engineering as Lifestyle and a Meritocracy of Difficulty: Two Pervasive Beliefs Among Engineering Students and Their Possible Effects. Paper presented at the Proceedings of the American Society for Engineering Education Annual Conference, Honolulu, Hawaii, June 24-27, 2007, Honolulu, Hawaii.

Strauss, A. L. (1987). Qualitative analysis for social scientists. Cambridge Cambridgeshire ; New York: Cambridge University Press.

Suresh, R. (2007). The Relationship between Barrier Courses and Persistence in Engineering. Journal of college student retention, 8(2), 215-239.

Titley, R. W., \& Titley, B. S. (1980). Initial Choice of College Major - Are Only the Undecided Undecided? Journal of College Student Development, 21(4), 293-298.

Turns, J., Cardella, M., Atman, C. J., Martin, J., Newman, J., \& Adams, R. S. (2006). Tackling the Research-to-Teaching Challenge in Engineering Design Education: Making the Invisible Visible. International Journal of Engineering Education, 22, 598-608. 
Appendix A - Learning Objectives and Outcomes

\section{Learning Outcomes for the First Introductory Course}

A. Develop an understanding of discipline-specific perspectives within the College of Engineering.

-Explore different approaches to a shared problem.

-Discern similarities and differences between discipline approaches.

B. Guide students to the informed choice of major within or outside of the College of Engineering -Identify personal skills and interests.

-Explore the range of disciplines a student wishes to focus.

C. Develop fundamental transferable skills applicable across the College of Engineering.

-Build study and critical thinking skills

-Develop visualization and data analysis abilities.

-Opportunities to gain a working knowledge of units.

-Familiarization with professional and ethical standards.

\section{Learning Objectives for the Second Introductory Course}

A. Develop analytic and technical engineering skills through programming and circuit building.

-Explore engineering tools including novel ones.

-Develop insights into key engineering principles spanning all disciplines.

-Build mindfulness and awareness of multiple programming environments and/or languages.

-Develop confidence and experience in algorithmic problem solving.

-Develop a knowledge of component integration to create functional subsystems.

B. Develop data collection and analysis skills.

-Build skills interfacing hardware and software.

-Choose between and develop competence using multiple analysis platforms, such as Excel, Matlab, Arduino, etc.

C. Team formation and collaboration 
-Explore different roles within a team.

\section{Learning Objectives for Third Introductory Course}

A. Get an introduction to the design process (user needs / requirements / design / evaluate / iterate).

-Mathematically (and/or algorithmically model an engineering problem.

-Evaluate the trade-off of different potential solutions to an engineering problem

-Begin understanding the complexity of design by evaluating user needs (needfinding), regulatory standards, resource constraints, societal needs, cost analysis.

B. Effectively work/contribute interdisciplinary teams to solve complex engineering problems -Work in a team to implement/refine/definite/design/develop a solution to an engineering problem

-Work on a team to define a problem, build a system, and analyze performance of the system relative to the stated goals.

-Understand that real solutions to major problems involve multiple skills and disciplines.

-Adapt and apply resources and skills from other courses to creatively solve a new problem.

-Develop interpersonal skills

C. Developing students as engineers and scientists by introducing methods for synthesizing existing knowledge with discovery of new knowledge in a safe and structured space.

-Provide a framework to encounter and develop and address emergent engineering challenges, and develop creativity.

D. Communicate orally and visually and in writing to document the process to solve a problem and the results of the project for technical and non-technical audiences. 